\title{
Multifunctional organic-inorganic hybrids based on cellulose acetate and 3-glycidoxypropyltrimethoxysilane
}

\author{
Robson R. Silva ${ }^{1} \cdot$ Denise T. B. Salvi $^{1} \cdot$ Molíria V. Santos $^{1} \cdot$ Hernane S. Barud $^{2}$ • \\ Lippy F. Marques $^{3} \cdot$ Silvia H. Santagneli ${ }^{1}$ Agnieszka Tercjak ${ }^{4} \cdot$ Sidney J. L. Ribeiro ${ }^{1}$
}

Received: 27 February 2016/Accepted: 21 May 2016/Published online: 2 June 2016

(C) Springer Science+Business Media New York 2016

\begin{abstract}
Organic-inorganic hybrid films have been prepared from cellulose acetate (CA) and 3-glycidoxypropyltrimethoxysilane (GPTMS). Flexible films were fashioned with high relative content of GPTMS (up to $70 \mathrm{wt} \%$ ) and exhibited high transparency in the visible/near-infrared region. The atomic force microscopy images of hybrid films display the presence of nanometric globular-like domains with size dependent and number dependent of the content of GPTMS. X-ray diffraction (XRD) patterns showed decreasing crystallinity of CA hybrid counterpart with increasing amounts of GPTMS. Spectroscopy results (vibrational spectroscopy FTIR and Raman scattering, ${ }^{13} \mathrm{C}$ and ${ }^{29} \mathrm{Si} \mathrm{NMR} \mathrm{spectra)} \mathrm{suggest} \mathrm{that} \mathrm{epoxy} \mathrm{groups} \mathrm{mostly}$ remain intact and significant amount of methoxysilane groups is available after addition of GPTMS in CA. From ${ }^{29} \mathrm{Si}$ NMR results, all compositions showed the presence of non-hydrolized GPTMS molecules or having mono- and disubstituted siloxane bonds. For highest relative content of GPTMS (i.e., 50 wt\%), a considerably high amount of nonhydrolized $\left(\mathrm{T}^{0}\right)$ is observed. Moreover, the addition of GPTMS leads to an increase in the thermal stability as
\end{abstract}

Sidney J. L. Ribeiro

sidney@iq.unesp.br

1 Institute of Chemistry, São Paulo State University, CP 355, Araraquara, SP 14801-970, Brazil

2 Centro universitário de Araraquara - UNIARA, Araraquara, SP 14801-320, Brazil

3 Instituto de Química, Universidade Estadual do Rio de Janeiro, Rio de Janeiro, RJ 20550-900, Brazil

4 Group 'Materials + Technologies' (GMT), Department of Chemical and Environmental Engineering, Engineering College of Gipuzkoa, University of the Basque Country (UPV/EHU), Plaza Europa 1, 20018 Donostia-San Sebastián, Spain compared to pure CA. Luminescent films were obtained by incorporating luminescent $\left[\mathrm{Eu}(\mathrm{TTA})_{3}\left(\mathrm{H}_{2} \mathrm{O}\right)_{2}\right]$ complex (TTA $=$ thenoyltrifluoroacetonate) into the hybrid films. Spectroscopic parameters did not significantly change with the incorporation of luminescent complex, suggesting application in photonics. The ${ }^{5} \mathrm{D}_{0}$ states quantum efficiency was observed to be the same for the neat complex and the luminescent hybrid film, suggesting a weak interaction with the host.

\section{Graphical Abstract}

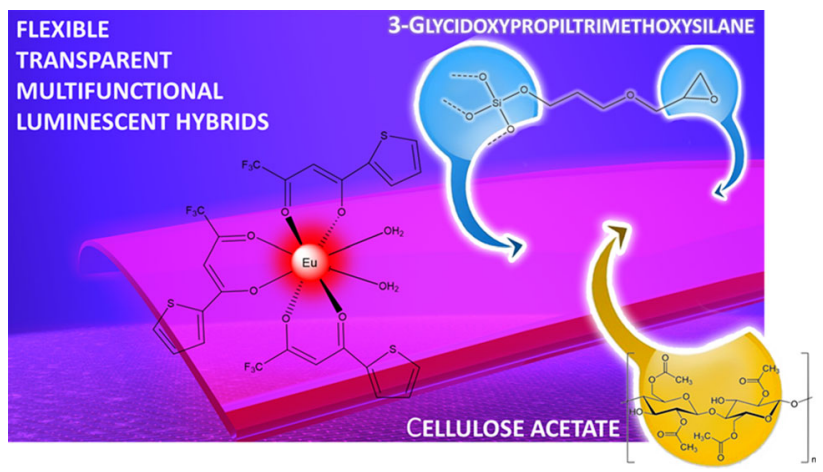

Keywords Organic-inorganic hybrids - Cellulose acetate . 3-Glycidoxypropyltrimethoxysilane · Europium .

Photoluminescence

\section{Introduction}

The past decade has witnessed steady growth of academic and industry interest on the development of new functionalized hybrid materials with high content of 
biopolymers [1, 2]. Biopolymers provide remarkable biocompatibility, eco-friendliness processability and comprise the best current alternatives to traditional non-biodegradable polymers. Among them, cellulose is the most naturally occurring biopolymer in the world. Cellulose-based materials have triggered great interest in the development of highly valuable industrial outcomes due to their appealing properties including hydrophilicity, semicrystalline structure and high mechanical strength [4]. Despite the wide variety of end uses, neat cellulose polymer is poorly soluble in common solvents. Most of derivatives are cellulose esters and ethers with improved solubility in aqueous and/ or organic solvents. Cellulose esters have good processability, enabling the fabrication of water-insoluble polymers films and fibers with excellent optical quality and stiffness. Cellulose acetate (CA) is one of the most important derivatives prepared by esterification of cellulose with main applications in $\mathrm{CO}_{2}$ filtration membranes, photographic and cinematographic films, protective film, fibers, protective coatings (e.g., protective film of the polarizing film of liquid crystal displays) and cigarette filters. CA is biodegradable and non-toxic being abundantly found in agricultural waste such as straw and biomass residues, and even chemically recycled newsprint has been explored as alternative source [4].

Despite the excellent optical properties of CA films, few reports have explored their practical use in photonic applications. For example, Lova et al. [5] prepared highquality flexible distributed Bragg reflectors constituted of ordered multilayers of $\mathrm{CA}$ and light scattering layer based on $\mathrm{ZnO}$ nanoparticles coated with polystyrene. Unno et al. [6] described the fabrication of nanogratings patterned by using thermal roll-to-roll nanoimprint technique on a $\mathrm{CA}$ film.

A broader use of CA in optics is mostly hampered by several limitations including relatively poor mechanical strength, low oxidation and solvent/chemical resistance. One potential route for overcoming these limitations is to combine additional organic and/or inorganic components with CA at molecular level in order to produce a hybrid with superior properties comparing to pure CA film. So far, sol-gel process is the most investigated approach to achieve organic/inorganic hybrid $(\mathrm{OIH})$ materials with improved properties. The key advantages of sol-gel processing concern the low-temperature processing in solution phase, purity, and homogeneity of the resulting materials. The fabrication of CA-based OIH films using sol-gel approach was firstly proposed by Kelley et al. [7, 8] by functionalization of neat CA polymer with organically modified alkoxysilanes. The authors evaluated the incorporation of alkoxysilanes possessing unsaturated polymerizable pendant groups (e.g., acrylate, vinyl), thiol and isothiocyanate groups in $\mathrm{CA}$ polymer seeking the fabrication of OIH films with high thermal stability and improved resistance against abrasion and organic solvent.

Gonçalves et al. $[9,10]$ demonstrated the feasibility to tailor a highly branched alkoxysilane CA-based OIH film by grafting pure CA film with 3-aminopropyltriethoxysilane cross-linked with pentaerythritol triacrylate components. The outcome concerns films insoluble in organic solvents and with a significant reduction in the dimensional changes in water when compared to pure CA films. Additionally, pure CA films have also been grafted with 3-aminopropyltrimethoxysilane in order to introduce amino groups as a pathway to covalently immobilize proteins. In a recent work, Heikkinen et al. [11] successfully evaluated the biotin-binding capacities of chimeric avidin, streptavidin, chicken avidin and rhizavidin immobilized on the surface of amino-functionalized CA films.

Achoundong et al. [12] have explored the grafting and cross-linking of vinyltrimethoxysilane on pristine CA films to produce transparent gas-permeable membranes with outperformance in high concentrations of $\mathrm{CO}_{2}$ and $\mathrm{H}_{2} \mathrm{~S}$ feeds. Noteworthy, the authors demonstrated that introduction of vinyl groups did not significantly affect the transparency of resulting hybrid films, while the flexibility was considerably improved.

In an effort to extend the practical use of cellulose acetate in photonics, we investigated the preparation of sol-gel hybrids with incorporation of 3-glycidoxypropyltrimethoxysilane, an organically modified alkoxide silane possessing terminal epoxy group. Epoxide groups can easily undergo ring-opening reactions via photo-, thermal and alkaline/acid catalytic polymerization generating polyethylene oxide (PEO) chains. Additionally, epoxy ring-opening can be used as coupling agent to covalently bind organic and inorganic compounds.

On the pursuit of evaluating their potential use in optical applications, free-standing red-emissive and yet highly transparent hybrid films were prepared by incorporating europium (III) tris-(2-thenoyltrifluoroacetate), $\left[\mathrm{Eu}(\mathrm{TTA})_{3}\left(\mathrm{H}_{2} \mathrm{O}\right)_{2}\right]$ complex. $\mathrm{Eu}^{3+}$ complexes are largely studied for various optical applications owing to their intense, UV-excited narrow emission bands in the red region with long excited-state lifetimes (i.e., in the milliseconds range). The mutual high solubility of both CA and $\left[\mathrm{Eu}(\mathrm{TTA})_{3}\left(\mathrm{H}_{2} \mathrm{O}\right)_{2}\right]$ complex in acetone is an advantageous feature to tailor functional and luminescent hybrid films with potential use in photonic materials.

\section{Experimental section}

Cellulose acetate $\left(\mathrm{Mn}=29,000 \mathrm{~g} \mathrm{~mol}^{-1}\right.$, acetyl content $\sim 40 \%$ ) was purchased from Fluka. 3-glycidoxypropyltrimethoxysilane and 2-thenoyltrifluoroacetone were 
purchased from Sigma-Aldrich. Hydrochloric acid and ammonium hydroxide were purchased from Synth. $\mathrm{Eu}_{2} \mathrm{O}_{3}$ was purchased from Lumintek.

\subsection{Synthesis of luminescent tris(2- thenoyltrifluoroacetonato)europium(III) dihydrate complex}

The synthesis of $\left[\mathrm{Eu}(\mathrm{TTA})_{3}\left(\mathrm{H}_{2} \mathrm{O}\right)_{2}\right]$ was based on a modified protocol reported by Charles et al. [13]. Firstly, an aqueous stock solution of europium chloride $(\mathrm{pH} \approx 5)$ was prepared by dissolving $\mathrm{Eu}_{2} \mathrm{O}_{3}(14.2 \mathrm{mmol}, 5.0 \mathrm{~g})$ in $\mathrm{HCl}$ $12 \mathrm{M}(85.2 \mathrm{mmol}, 7.12 \mathrm{~mL})$ at $100{ }^{\circ} \mathrm{C}$ under stirring (500 rpm). The concentration of aqueous solution of $\mathrm{EuCl}_{3} \cdot 6 \mathrm{H}_{2} \mathrm{O}$ was determined by EDTA titration with a value of $0.13 \mathrm{M}$. 2-thenoyltrifluoroacetone (TTA, $3.9 \mathrm{mmol}, 0.86 \mathrm{~g}), \mathrm{NH}_{4} \mathrm{OH} 18.08 \mathrm{M}(15 \mathrm{mmol}, 0.450 \mathrm{~mL})$ and $\mathrm{EuCl}_{3} \cdot 6 \mathrm{H}_{2} \mathrm{O} 0.13 \mathrm{M}(1.3 \mathrm{mmol}, 10.0 \mathrm{~mL})$ were dissolved in ethanol $(18.75 \mathrm{~mL})$ under vigorous stirring in a round-bottomed flask. After $3 \mathrm{~h}$, the resulting solid (i.e., $\left[\mathrm{Eu}(\mathrm{TTA})_{3}\left(\mathrm{H}_{2} \mathrm{O}\right)_{2}\right]$ complex) was precipitated by cooling the flask in ice bath. The precipitate was filtered off and recrystallized from acetone.

\subsection{Preparation of cellulose acetate/3- glycidoxypropyltrimethoxysilane hybrid films}

$0.25 \mathrm{~g}$ of CA was dissolved in $4 \mathrm{~mL}$ of acetone. After complete dissolution, GPTMS was added and the mixture was stirred for $1 \mathrm{~min}$. The solution was cast on flat petri dishes and covered with a thin aluminum foil. The samples were named as CA-GPTMS $\mathrm{x} \%$ with $\mathrm{x}=10-50 \%$ for different GPTMS weight percentage content.

\subsection{Preparation of luminescent cellulose acetate/3- glycidoxypropyltrimethoxysilane hybrid film}

In a beaker, $0.25 \mathrm{~g}$ of cellulose acetate was dissolved in $4 \mathrm{~mL}$ of acetone. Then, $150 \mu \mathrm{L}$ of GPTMS and $654 \mu \mathrm{L}$ of an acetone solution of $\left[\mathrm{Eu}(\mathrm{TTA})_{3}\left(\mathrm{H}_{2} \mathrm{O}\right)_{2}\right] 15 \mathrm{mM}$ were added dropwise. The resulting solution was placed on glass dishes $(\phi=10 \mathrm{~cm})$ and left to dry in ambient air (relative humidity of $\sim 35 \%$ ) during $24 \mathrm{~h}$.

\subsection{Instrumentation}

Absorption spectra were measured in the wavelength range from 200 to $2000 \mathrm{~nm}$ with a UV-visible spectrometer Cary 500 .

Scanning electron microscopic (SEM) images were taken in a field emission scanning electron microscope (FESEM, JEOL JSM-7500F). A thin film of carbon was sputtered onto the surface of the samples before the analysis. Atomic force microscopy (AFM) images were taken in an Agilent 5500-AC Mode III in the intermittent contact mode under ambient conditions, and using conventional silicon multipurpose cantilevers. All images were rendered using Gwyddion AFM analysis software. It is worth pointing out that the AFM and SEM imaging were performed on the surface of hybrid films generated in the liquid/air interface from the evaporation of solvent.

Fourier transform infrared spectroscopy (FTIR) analysis was performed in a Spectrum 2000 FTIR PerkinElmer spectrophotometer, equipped with a multiple reflection, horizontal Miracle attenuated total reflectance (ATR) attachment (ZnSe crystal). Spectra were collected over the range of $4000-600 \mathrm{~cm}^{-1}$ with an accumulation of 128 scans and resolution of $4 \mathrm{~cm}^{-1}$.

Raman spectra were recorded using a Raman Horiba Jobin-Yvon 118 model LabRAM HR 800 spectrometer, operating with $\mathrm{He}-\mathrm{Ne} 632.81 \mathrm{~nm}$ laser through a $100 \times$ objective lens and dispersed by a diffraction grating (600 lines $\mathrm{mm}^{-1}$ ) onto a cooled charge-coupled device (CCD) detector.

The ${ }^{29} \mathrm{Si}\left\{{ }^{1} \mathrm{H}\right\}$ cross-polarization magic angle spinning (CP-MAS), ${ }^{13} \mathrm{C}\left\{{ }^{1} \mathrm{H}\right\} \mathrm{CP}-\mathrm{MAS}$ and ${ }^{1} \mathrm{H}$ MAS spectra were obtained on a Bruker Avance III 400WB HD, operating at $9.4 \mathrm{~T}$, using a commercial double resonance $4 \mathrm{~mm}$. Typical spinning speeds were 10.0 and $12.0 \mathrm{kHz} .{ }^{29} \mathrm{Si}\left\{{ }^{1} \mathrm{H}\right\} \mathrm{CP}-\mathrm{MAS}$ spectra were measured with ${ }^{1} \mathrm{H}$ pulse length of 3.0 us, contact time of $3.5 \mathrm{~ms}$ and relaxation delay of $5 \mathrm{~s} .{ }^{13} \mathrm{C}\left\{{ }^{1} \mathrm{H}\right\} \mathrm{CP}-\mathrm{MAS}$ spectra were measured with ${ }^{1} \mathrm{H}$ pulse length of 2.8 us, contact time of $2.0 \mathrm{~ms}$ and relaxation delay of $2 \mathrm{~s}$. All spectra were acquired with two-pulse phase modulation (TPPM) proton decoupling during the data acquisition applying decoupling pulses of $5.8 \mu$ s length. The chemical shifts are reported relative to tetramethylsilane (TMS). Chemical shifts have an estimated error in \pm 0.1 .

$\mathrm{X}$-ray diffraction (XRD) patterns were obtained using a Kristalloflex Siemens diffractometer with a Ni filer and $\mathrm{CuK} \alpha$ radiation from $4^{\circ}$ to $50^{\circ}$, step scan of $0.02^{\circ} 2 \theta, \lambda \mathrm{Cu}-$ $\mathrm{k} \alpha$ monochromatized by a graphite crystal, divergence slit width $=1 / 2^{\circ}$, scattering slit $=1 / 2^{\circ}$, divergence heightlimiting slit width $=5 \mathrm{~mm}$ and reception slit $=0.3 \mathrm{~mm}$.

Thermogravimetric (TG) curves were obtained from SDT equipment from TA Instruments. The conditions used in the experiments were: synthetic air at a flow rate of $100 \mathrm{~mL} \mathrm{~min}{ }^{-1}$, heating rate of $20^{\circ} \mathrm{C} \mathrm{min}^{-1}$ from $20^{\circ}$ to $600{ }^{\circ} \mathrm{C}$ and alumina pans.

The photoluminescence spectra were recorded in Horiba Jobin-Yvon Fluorolog spectrofluorometer model FL3-222, equipped with a Hamamatsu R928 photomultiplier and Xe lamp $(450 \mathrm{~W})$ using front face mode with resolution of $0.5 \mathrm{~nm}$. 


\section{Results and discussion}

Figure 1a shows the picture of a bended CA-GPTMS freestanding film exhibiting high transparency. In general, the hybrid films featured high transmittance $(>85 \%)$ in the visible/near-infrared region for all composition investigated as displayed in Fig. 1b. The optical transmittance spectra show that both pristine CA and CA-GPTMS films absorb in the region below $300 \mathrm{~nm}$. The addition of GPTMS did not place substantial deleterious effect on the optical properties resulting hybrid films. Additionally, SEM images depicted in Fig. 2 clearly display that the surface of the films was homogeneous, indicating compatibility between CA and GPTMS, thereby contributing to the high transparency observed for all investigated compositions.

AFM height and phase images obtained for pristine CA film and CA-GPTMS films containing 20 and $50 \mathrm{wt} \%$ GPTMS are shown in Fig. 3. AFM phase image of pristine CA film shown in Fig. 3b unveiled typical regular topography at nanometric scale. Pristine CA film is homogenous on the analyzed surface, and its average roughness extracted from AFM height image is very low $(4.7 \pm 2 \mathrm{~nm})$. Addition of the $20 \mathrm{wt} \%$ of GPTMS led to considerable changes in the surface structure. The surface structure changed to homogeneously dispersed globularlike morphology with average domain size smaller than $30 \mathrm{~nm}$. The average roughness extracted from AFM height images decreased to $2 \pm 0.7 \mathrm{~nm}$. As shown in Fig. $3 \mathrm{~F}$, the addition of $50 \mathrm{wt} \%$ of GPTMS led to an increase in the number and size of the globular-like domains. The average size of globular-like domains became larger than $100 \mathrm{~nm}$, and roughness of hybrid film increased to $7.5 \pm 1 \mathrm{~nm}$. The increase in globular-like domains may have a deleterious effect in the optical properties of CA-GPTMS $50 \%$ films addressed by a slight decrease in the transmittance as a result of light scattering process.

Figure 3 shows ATR-FTIR spectra. The main feature of $\mathrm{CA}$ is the presence of band at $1738 \mathrm{~cm}^{-1}$ assigned to symmetric stretching of the carbonyl $(\mathrm{C}=\mathrm{O})$ from acetyl group $\left(\mathrm{CH}_{3} \mathrm{C}(\mathrm{O}) \mathrm{O}-\right)$ [14]. Bands observed at 1222, 1160 and $1030 \mathrm{~cm}^{-1}$ could be assigned to asymmetric stretching of $\mathrm{C}-\mathrm{O}, \mathrm{C}-\mathrm{O}-\mathrm{C}$ glycosidic linkage and asymmetric $\mathrm{C}-\mathrm{O}-$ $\mathrm{C}$ bond stretching from the pyranose ring, respectively [14]. Noteworthy, the band at $1222 \mathrm{~cm}^{-1}$ gets sharper as GPTMS content is increased. Upon the addition of GPTMS, narrowing and relative increase is observed for the band at $1160 \mathrm{~cm}^{-1}$. The assignment of this band is related to the overlapping of $\mathrm{CH}_{3}$ rocking combined with $\mathrm{C}-\mathrm{O}$ stretching modes of methoxy groups [15]. Bands related to silica net vibration modes were hardly observed, suggesting that GPTMS could remain non-hydrolyzed.
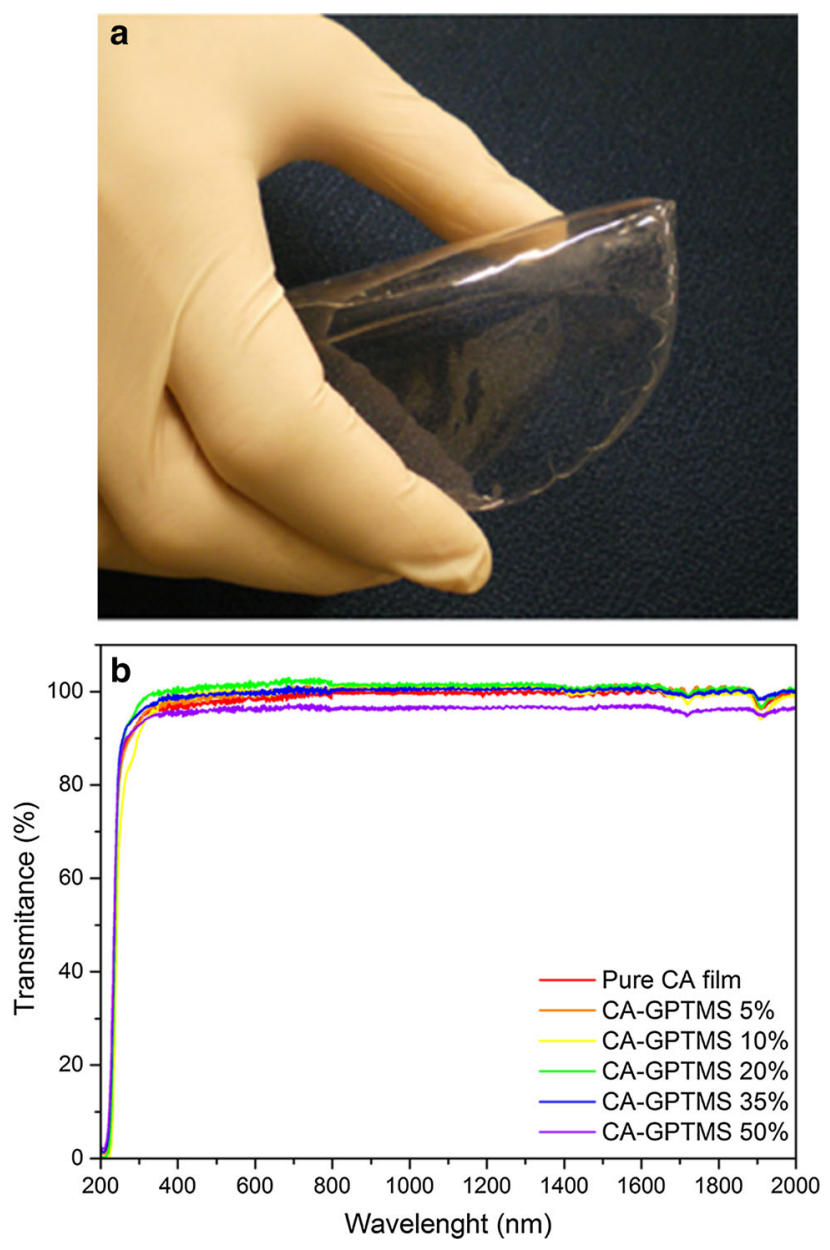

Fig. 1 a Picture of transparent and flexible free-standing film of CAGPTMS hybrid, b Ultraviolet-visible-near infared (UV-VisNOR) transmittance spectra of pristine CA and GPTMS hybrid films. The films were highly transparent $(>85 \%)$ for all composition from ultraviolet to the near infrared (Color figure online)

High-intensity bands associated with epoxy ring vibrations modes occur in the $800-700 \mathrm{~cm}^{-1}$ region. The band at $855 \mathrm{~cm}^{-1}$ refers to $\mathrm{C}-\mathrm{O}$ torsion and $\mathrm{C}-\mathrm{C}$ stretching of epoxy ring, while the band at $818 \mathrm{~cm}^{-1}$ is assigned to $\mathrm{CH}_{2}$ rocking of propyl chain coupled with $\mathrm{Si}-\mathrm{O}$ stretching. The band observed at $902 \mathrm{~cm}^{-1}$ with moderate intensity in pristine CA films has been assigned to glycosidic vibrations [16] mixed with out-of-plane O-H bending of water. Moreover, a slight increase in intensity followed by narrowing of this band is observed with increasing content of GPTMS which could be attributed to the coupling with $\mathrm{C}-$ $\mathrm{O}$ and $\mathrm{C}-\mathrm{C}$ stretching besides $\mathrm{C}-\mathrm{O}$ torsion of epoxy ring [15]. Additionally, $\mathrm{C}-\mathrm{O}$ stretching mixed with $\mathrm{CCO}$ scissoring vibrations from pure epoxy ring was assigned to the emerging band at $762 \mathrm{~cm}^{-1}$ [15].

Figure 4 displays Raman spectra. A relatively strong Raman band at $1256 \mathrm{~cm}^{-1}$ is observed in the all CA- 

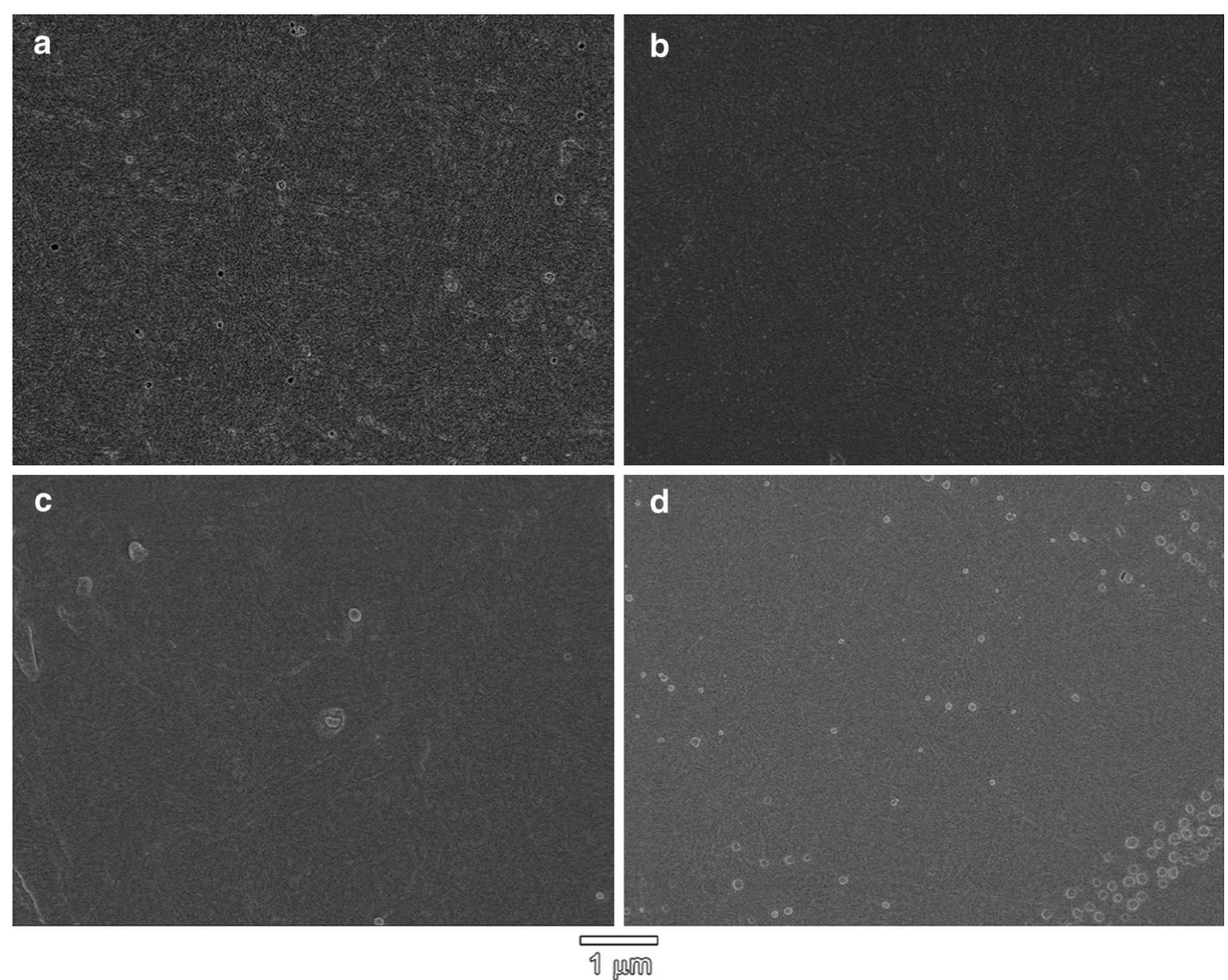

d.

Fig. 2 FE-SEM images of a pristine CA film and hybrid films of CA with different contents of GPTMS, b 20 wt $\%$, c 35 wt $\%$, and d 50 wt $\%$

GPTMS hybrid films. This band is assigned to $\mathrm{C}-\mathrm{H}$ rock and $\mathrm{C}-\mathrm{C}$ stretching vibration of epoxy ring [15]. An additional contribution of this band could be addressed to the coupling of $\mathrm{Si}-\mathrm{CH}_{2}-\mathrm{R}$ bending vibrations from nonhydrolyzed GPTMS molecules.

Bands observed in the region between 1500 and $1300 \mathrm{~cm}^{-1}$ comprise the vibration modes of cellulose backbone of $\mathrm{CA}$ polymer. This region is essentially described by deformation modes of $\mathrm{CH}_{2}, \mathrm{H}-\mathrm{C}-\mathrm{C}, \mathrm{H}-\mathrm{C}-\mathrm{O}$ and $\mathrm{C}-\mathrm{O}-\mathrm{H}$ vibrations at $1378 \mathrm{~cm}^{-1}$ and by the deformation of $\mathrm{CH}_{3}$ groups within acetyl groups [17, 19] at $1434 \mathrm{~cm}^{-1}$. A discrete band at $1485 \mathrm{~cm}^{-1}$ is also observed with the increase in GPTMS content in the hybrid films and is assigned to $\mathrm{CH}_{2}$ scissoring and $\mathrm{CH}$ rocking in epoxy ring [15]. In addition, the epoxy ring vibrations are also observed at 763 and $759 \mathrm{~cm}^{-1}$ which are assigned to symmetric stretching of aliphatic ether linkage of epoxy group [15].

A relatively strong band observed for all films at $910 \mathrm{~cm}^{-1}$ is associated with stretching and bending modes of C-O single bond [17] of CA polymer. Bands at 1160 and $1083 \mathrm{~cm}^{-1}$ are associated with asymmetric and symmetric pyranose ring breathing vibration of cellulose [19], respectively.

The doublet band observed at 644 and $612 \mathrm{~cm}^{-1}$ arises with the increase in the GPTMS content. This band has been assigned to coupled symmetric and asymmetric stretching vibrations of $\left(-\mathrm{Si}\left(\mathrm{OCH}_{3}\right)_{3}\right)$ group. In a previous work, Riegel et al. [20] monitored the intensity of $644 \mathrm{~cm}^{-1}$ Raman band as a tool to investigate the hydrolysis of GPTMS hybrids containing 3-aminopropyltrimethoxysilane. The authors inferred that the intensity of the Raman band at $644 \mathrm{~cm}^{-1}$ is associated with the amount of the non-hydrolyzed trimethoxysilane molecules $\left(-\mathrm{Si}\left(\mathrm{OCH}_{3}\right)_{3}\right)$. The presence of this band in the $\mathrm{CA}-$ GPTMS spectra also suggests that GPTMS molecules could mostly remain non-hydrolyzed.

Figure 5 shows ${ }^{13} \mathrm{C}\left\{{ }^{1} \mathrm{H}\right\}$ CP-MAS NMR spectra. The spectrum of CA shows broad resonance lines with assignments based on [21, 22]. The assignments are identified in the spectrum as specified in top portion of Fig. 5. Peaks observed at 21 and 40 ppm of carbon acetyl group $C^{5}$ and $\mathrm{C}^{7}$ are present in all films spectra. The peaks observed at 42.6 and 49.7 ppm (positions $\mathrm{C}^{\mathrm{VI}}$ and $\mathrm{C}^{\mathrm{V}}$, respectively) are attributed to epoxy groups. The relative intensity is the same for all CA-GTMS hybrid films, indicating that there was no polymerization process. It is interesting to highlight that the line width of the peaks of GPTMS keeps narrow to all concentrations in the hybrid films, suggesting a high mobility of epoxy group.

Results from vibrational and NMR spectra emphasize the presence of unreacted epoxy ring of GPTMS molecule 

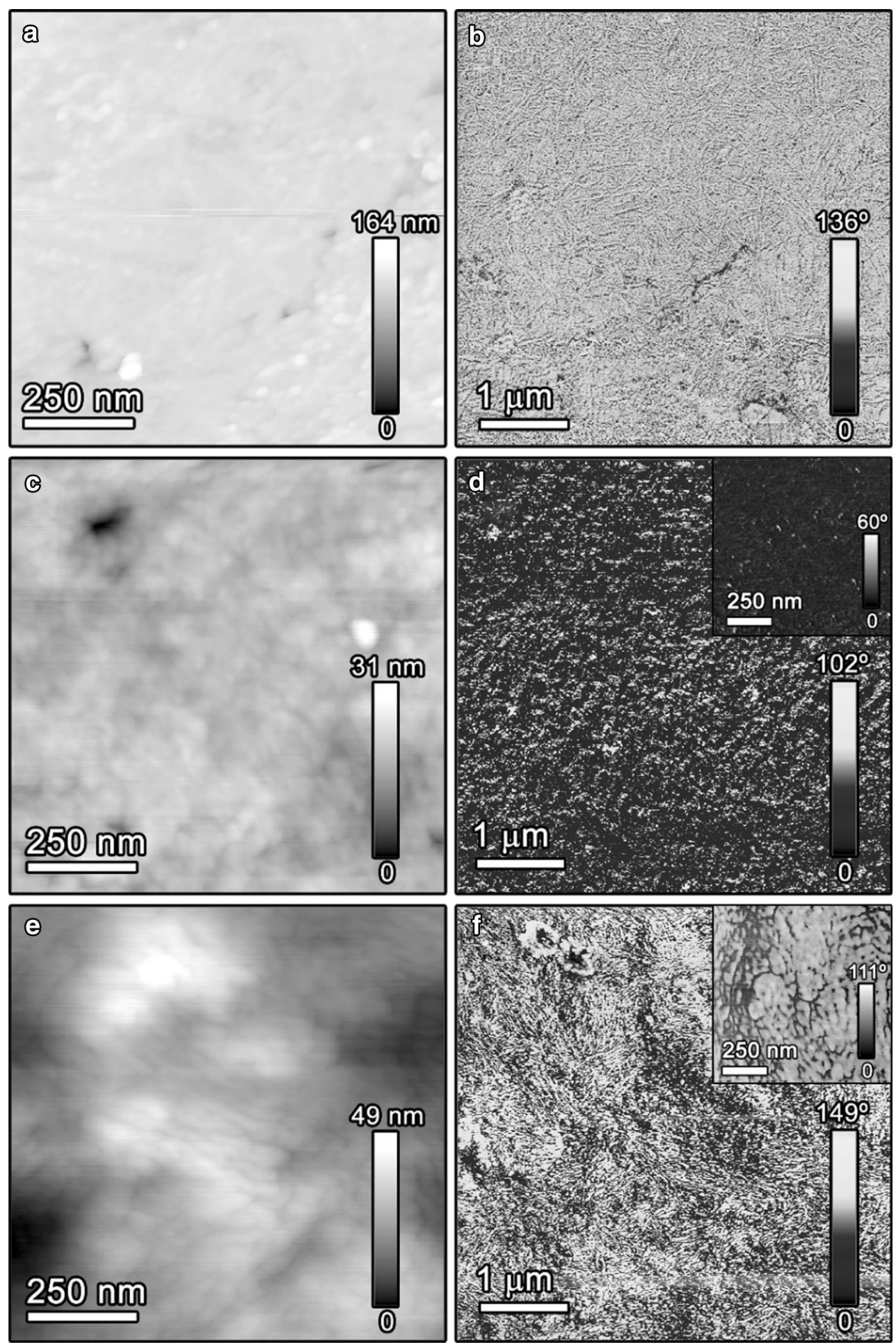

Fig. 3 Height AFM images of a pristine CA film, c CA-GPTMS $20 \%$ and e CA-GPTMS $50 \%$. Phase AFM images are pictured in (b) pristine CA films, d CA-GPTMS $20 \%$ and f CA-GPTMS $50 \%$.

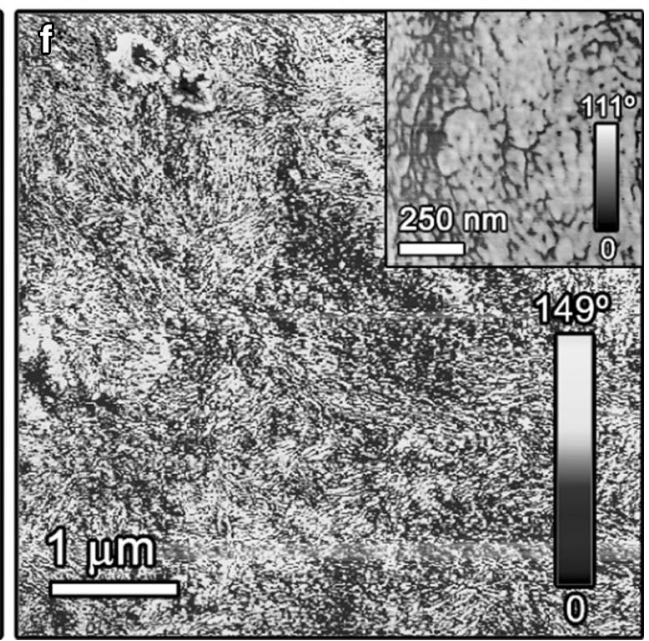

The inset in (d) and (f) show amplified regions of CA-GPTMS $20 \%$ and CA-GPTMS $50 \%$, respectively

in the hybrid films. The presence of epoxy groups enables a new pathway to chemically modify the CA films. Beyond that, a cross-linked hybrid matrix is feasible to be

achieved by ring-opening reactions of epoxy groups, which in turn can be conducted by exposing the CAGPTMS films to ultraviolet light, thermal activation or 


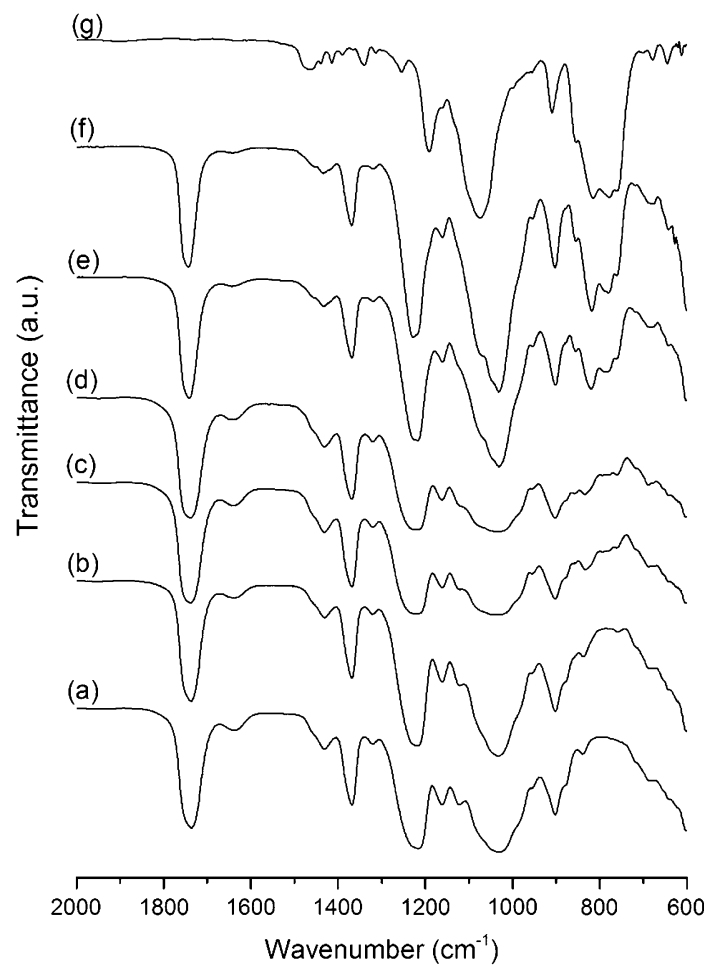

Fig. 4 ATR-FTIR of $a$ pure CA film, $b$ CA-GPTMS $5 \%, c$ CAGPTMS $10 \%, d$ CA-GPTMS $20 \%, e$ CA-GPTMS $35 \%, f$ CAGPTMS $50 \%$ and $g$ liquid GPTMS

nucleophilic substitution reaction under alkaline/acidy media.

Hydrolysis and condensation reactions of GPTMS were investigated by ${ }^{29} \mathrm{Si}$ NMR. $\mathrm{T}^{\mathrm{n}}$ code is used where $n$ indicates the number of bridged $\mathrm{Si}$ atoms [23]. Figure 6 shows

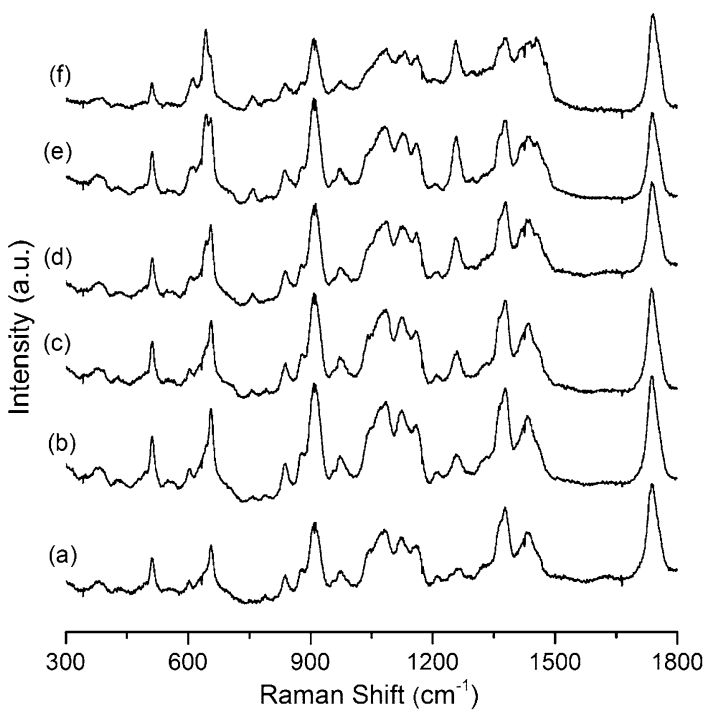

Fig. 5 Raman spectra of $a$ pristine CA film, $b$ CA-GPTMS $5 \%$, $c$ CA-GPTMS $10 \%, d$ CA-GPTMS $20 \%, e$ CA-GPTMS $35 \%$ and $f$ CA-GPTMS $50 \%$ the ${ }^{29} \mathrm{Si}\left\{{ }^{1} \mathrm{H}\right\} \mathrm{CP}-\mathrm{MAS}$ NMR spectra. Three resonance lines are observed in the ${ }^{29} \mathrm{Si}\left\{{ }^{1} \mathrm{H}\right\}$ CP-MAS spectra. The peaks at $-41,-48$ and $-58 \mathrm{ppm}$ are assigned to $\mathrm{T}^{0}, \mathrm{~T}^{1}$ and $\mathrm{T}^{2}$ siloxane species, respectively $[24,25]$-in the CAGPTMS film. Silicon linked with three siloxane units $\left(\mathrm{T}^{3}\right)$ was hardly observed. The ${ }^{29} \mathrm{Si}\left\{{ }^{1} \mathrm{H}\right\}$ CP-MAS NMR data indicate that hydrolysis and condensation reactions of silicon methoxides groups from GPTMS molecules partially took place during the preparation of the hybrid films. Approximately, the same relative amount of $\mathrm{T}^{0}, \mathrm{~T}^{1}$ and $\mathrm{T}^{2}$ units could be observed for hybrid films with GPTMS content lower than $35 \mathrm{wt} \%$. With further increase in GPTMS relative content $(50 \mathrm{wt} \%)$, the contribution of $\mathrm{T}^{0}$ units increases.

Figure 7 shows $\mathrm{X}$-ray diffraction patterns. The pattern obtained for pure CA film shows three main broad peaks observed at $8.8^{\circ}, 10.7^{\circ}$ and $17.8^{\circ}$. The peak located at $8.8^{\circ}$ is known as the main characteristic of semicrystalline acetylated derivative cellulose. This peak position indicates the generation of disorder when cellulose is acetylated. The disorder is due to the projection of the acetyl groups along the axes (causing interfibrillar distance to increase) and is also related to the breakdown of microfibrillar structures. Similar results were found by Barud et al. [26] in the acetylation of bacterial cellulose.

The peak at $2 \theta=10^{\circ}$ is a well-known feature appearing for acetylated cellulose [27]. The peak at around $17.8^{\circ}$ is known as the van der Waals halo. This broad peak is observed in polymers and corresponds to the polymeric chain packing due to van der Waals forces. This diffraction pattern observed for the pure CA film corresponds to the structure of the acetylated materials [28]. Besides, Fig. 7a shows that the XRD pattern of pristine CA films shows partial crystalline structure.

Figure $7 \mathrm{~b}-\mathrm{d}$ shows XRD patterns obtained for CAGPTMS hybrids containing 5, 10 and $20 \mathrm{wt} \%$ of GPTMS, respectively. The diffractograms are similar to the one observed for the pristine CA film (Fig. 7a), except the slightly narrower peaks at $8.8^{\circ}, 10.8^{\circ}$ and $13.6^{\circ}$.

Figure 7e-f shows results obtained for hybrids containing 35 and $50 \mathrm{wt} \%$ of GPTMS. For CA-GPTMS $35 \%$ (Fig. 7e), peaks near $8.8^{\circ}, 10.8^{\circ}$ and $13.6^{\circ}$ are merged into a broadened one, centered around $8.4^{\circ}$. For CA-GPTMS $50 \%$ (Fig. 7f), the broad peak near $8.4^{\circ}$ becomes less intense (in comparison with the broad peak near $20^{\circ}$ ), which means the crystallinity was diminished.

It can be argued that for the CA-GPTMS 5, 10 and $20 \%$ sol-gel hybrids, the GPTMS addition slightly increases the crystallinity of cellulose acetate film. For higher amounts of GPTMS (i.e., CA-GPTMS 35 and $50 \%$ ), the inverse is observed. In this case, GPTMS may interact in a higher extent with CA polymer and play a key role on the disarrangement among CA chains leading to 


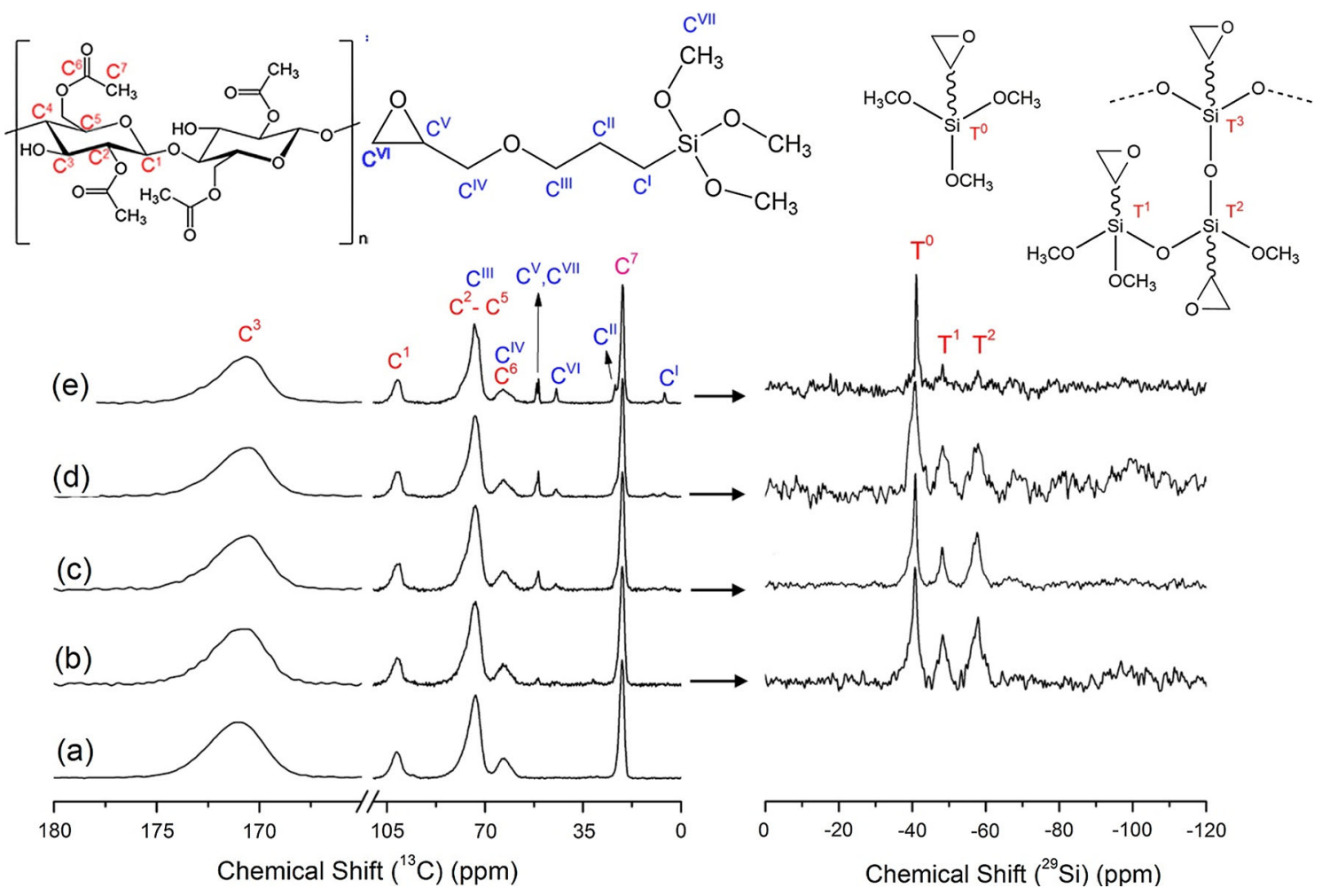

Fig. 6 In the upper panel, the assignments of the ${ }^{13} \mathrm{C}$ NMR and ${ }^{29} \mathrm{Si}\left\{{ }^{1} \mathrm{H}\right\}$ CP-MAS NMR signals are identified on the chemical structures of GPTMS and CA. The bottom left panel displays the ${ }^{13} \mathrm{C}$ NMR of $a$ pristine CA, $b$ CA-GPTMS $5 \%, c$ CA-GPTMS $20 \%$,

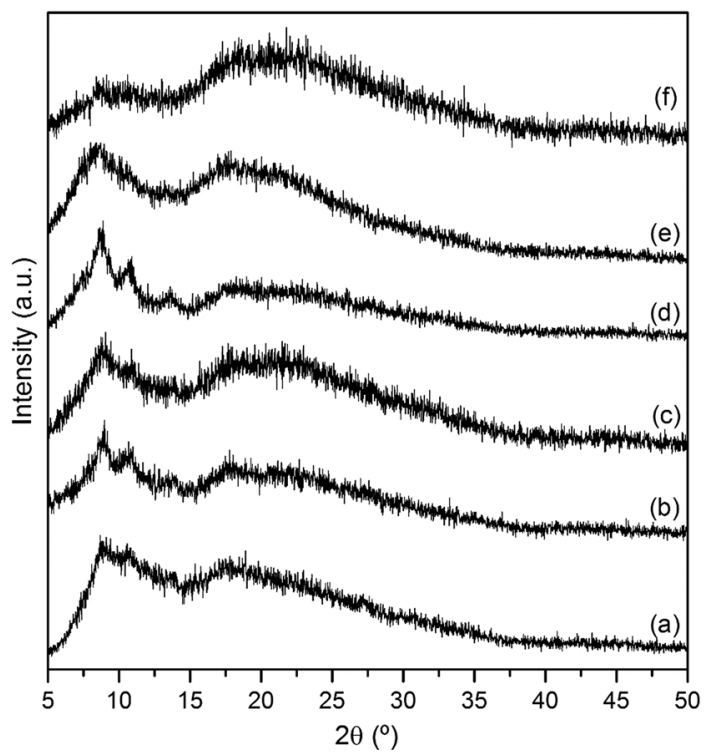

Fig. 7 X-ray diffraction of $a$ pure CA film, $b$ CA-GPTMS $5 \%$, $c$ CA-GPTMS $10 \%, d$ CA-GPTMS $20 \%, e$ CA-GPTMS $35 \%$, $f$ CA-GPTMS $50 \%$

amorphous hybrid films. Below $20 \mathrm{wt} \%$ of GPTMS content, it may partially induce the assembly and eventual $d$ CA-GPTMS $35 \%$ and $e$ CA-GPTMS $50 \%$ films. The solid-state ${ }^{29} \mathrm{Si}\left\{{ }^{1} \mathrm{H}\right\}$ CP-MAS NMR spectra of CA-GPTMS hybrids are displayed in the bottom right panel (Color figure online)

packing of CA chains. In this case, the concentration of GPTMS is not sufficient to produce extended silica network mostly ruled by spatial restriction due to the high relative content of CA chains.

The TG/DTG curves are displayed in Fig. 8. The thermal stability of pristine CA and representative samples CAGPTMS $5 \%$ and CA-GPTMS $50 \%$ were evaluated in oxidative atmosphere in an attempt to estimate the inorganic residues [26]. TG curve for pristine CA film displays two thermal events. The first event comprises the range from ambient temperature to $120^{\circ} \mathrm{C}$, whose mass loss is mostly ascribed to the evaporation of residual solvent (i.e., acetone). The second mass loss event occurs at around $\left(\sim 370{ }^{\circ} \mathrm{C}\right)$ is due to polymer decomposition of CA backbones $[4,26]$. As expected, there is no residue at $600{ }^{\circ} \mathrm{C}$.

The TGA curves profiles for CA-GPTMS $5 \%$ and CAGPTMS $50 \%$ samples exhibit two additional events. From room temperature to $120^{\circ} \mathrm{C}$, the weight loss can be attributed to residual acetone desorption plus evaporation of water produced as by-product of eventual hydrolysis/condensation of GPTMS molecules. There are additional weight loss events starting at $120{ }^{\circ} \mathrm{C}$ and ending at around $250{ }^{\circ} \mathrm{C}$ addressed to removal of monomeric physisorbed silanes [30]. 
For CA-GPTMS composite samples, the main thermal event is due to simultaneous decompositions of GPTMS molecules and neat $\mathrm{CA}$ polymer components which have similar decomposition temperature $\left(\sim 370{ }^{\circ} \mathrm{C}\right)$ [29]. For CA-GPTMS samples, the residue at $600{ }^{\circ} \mathrm{C}$ can be associated with the formation of silicon derivatives.

In order to estimate the potential use of functional CAGPTMS hybrids in optical applications, luminescent films comprising transparent CA-GPTMS $40 \%$ hybrid containing $2 \mathrm{wt} \%$ luminescent [Eu(TTA $)_{3}\left(\mathrm{H}_{2} \mathrm{O}\right)_{2}$ ] complex were prepared. Figure 9 shows the ATR-FTIR spectra of pristine CA-GPTMS $40 \%$ hybrid film, [Eu(TTA $)_{3}\left(\mathrm{H}_{2} \mathrm{O}\right)_{2}$ ] complex and CA-GPTMS $40 \%$ hybrid containing $2 \mathrm{wt} \%$ luminescent $\left[\mathrm{Eu}(\mathrm{TTA})_{3}\left(\mathrm{H}_{2} \mathrm{O}\right)_{2}\right]$. The ATR-FTIR spectrum of $\left[\mathrm{Eu}(\mathrm{TTA})_{3}\left(\mathrm{H}_{2} \mathrm{O}\right)_{2}\right]$ complex shows bands at 1501, 1481,1415 and $1355 \mathrm{~cm}^{-1}$ as fine and intense bands assigned to $v(\mathrm{C}=\mathrm{C}, \mathrm{C}=\mathrm{S})$ of thienyl heterocycle. Characteristic stretching vibration modes of the enol tautomer form of $\beta$-diketonate features peaks narrow and intense bands at $1601 \mathrm{~cm}^{-1}(\mathrm{v}(\mathrm{C}=\mathrm{O})), 1537$ and $1505 \mathrm{~cm}^{-1}$ $(v(\mathrm{C}=\mathrm{O}, \mathrm{C}=\mathrm{C}))$. The peaks at 1280,740 and $712 \mathrm{~cm}^{-1}$ are assigned to stretching and bending vibration modes of $\mathrm{CF}_{3}$.

ATR-FTIR spectrum of CA-GPTMS $40 \%$ hybrid film containing $2 \mathrm{wt} \%$ of $\left[\mathrm{Eu}(\mathrm{TTA})_{3}\left(\mathrm{H}_{2} \mathrm{O}\right)_{2}\right]$ presented in Fig. 9c can be considered as the result of the convolution of the spectra of CA-GPTMS $40 \%$ hybrid film and [Eu(TTA $\left.)_{3}\left(\mathrm{H}_{2} \mathrm{O}\right)_{2}\right]$ compound. In addition, the ATR-FTIR spectrum of doped hybrid film do not show the formation of any additional bands if compared with ATR-FTIR spectra of pristine CA-GPTMS $40 \%$ hybrid and pristine $\left[\mathrm{Eu}(\mathrm{TTA})_{3}\left(\mathrm{H}_{2} \mathrm{O}\right)_{2}\right]$, which confirm lack of chemical bonds between the components. The ATR-FTIR spectra

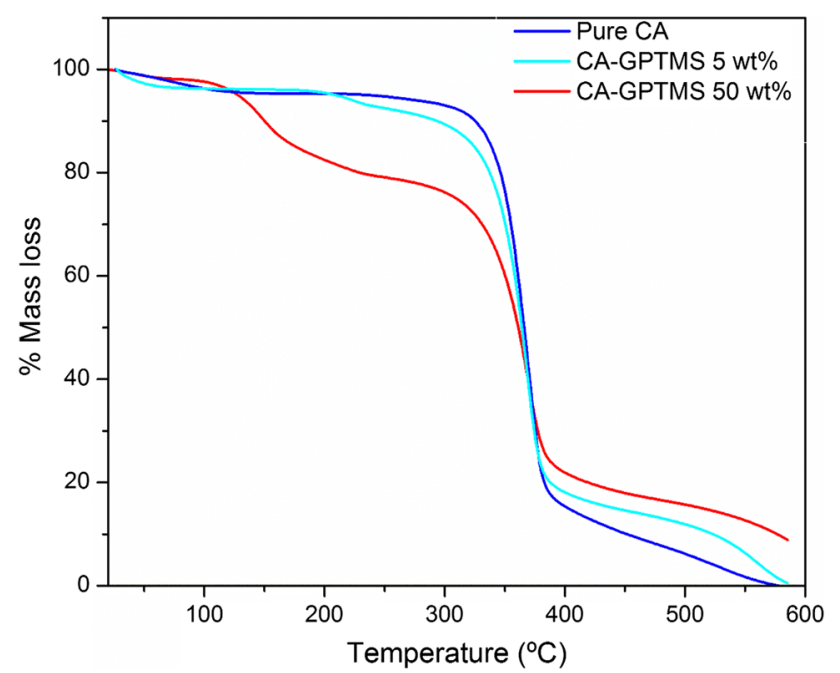

Fig. 8 Thermogravimetric curves of pure CA, CA-GPTMS $5 \%$, and CA-GPTMS $50 \%$ films (Color figure online)
CA-GPTMS luminescent films confirm the presence of $\left[\mathrm{Eu}(\mathrm{TTA})_{3}\left(\mathrm{H}_{2} \mathrm{O}\right)_{2}\right]$ complex.

Figure 10a shows the absorption spectra obtained for pristine CA-GPTMS $40 \%$ hybrid film and luminescent CA-GPTMS hybrid film. The absorption spectrum of doped hybrid film is characterized by two relatively resolved bands centered at 269 and $339 \mathrm{~nm}$ which are assigned to the ligand-centered $\mathrm{S}_{0} \rightarrow \mathrm{S}_{1}\left(\pi, \pi^{*}\right)$ transition of the aromatic moiety in the TTA ligands [31, 32]. The picture featured in Fig. 10b shows an intense orange-red emission of transparent CA-GPTMS $40 \%$ hybrid doped with $\left[\mathrm{Eu}(\mathrm{TTA})_{3}\left(\mathrm{H}_{2} \mathrm{O}\right)_{2}\right]$ complex placed over a paper sheet under exposure of commercial UV light.

Figure 10c shows the normalized excitation spectra obtained for the $\left[\mathrm{Eu}(\mathrm{TTA})_{3}\left(\mathrm{H}_{2} \mathrm{O}\right)_{2}\right]$ complex and luminescent CA-GPTMS hybrid film registered at $300 \mathrm{~K}$ in $250-500 \mathrm{~nm}$ range by monitoring the $\mathrm{Eu}^{3+}$ emission at $611 \mathrm{~nm}$. These spectra exhibit broad bands, with the maximum peaking around $325 \mathrm{~nm}$ which is attributable to the ligand-centered $\mathrm{S}_{0} \rightarrow \mathrm{S}_{1}\left(\pi, \pi^{*}\right)$ transition of TTA ligand [32], as already observed in the absorption spectra. This broad absorption band overlaps some $4 f-4 f$ absorption bands corresponding to the characteristic transitions of $\mathrm{Eu}^{3+}$ ion, such as ${ }^{7} \mathrm{~F}_{0} \rightarrow{ }^{5} \mathrm{G}_{6} \quad(361 \mathrm{~nm}),{ }^{7} \mathrm{~F}_{0} \rightarrow{ }^{5} \mathrm{H}_{4}$ $(374 \mathrm{~nm}),{ }^{7} \mathrm{~F}_{0} \rightarrow{ }^{5} \mathrm{~L}_{6}(394 \mathrm{~nm})$ and ${ }^{7} \mathrm{~F}_{0} \rightarrow{ }^{5} \mathrm{D}_{3}(415 \mathrm{~nm})$, except the ${ }^{7} \mathrm{~F}_{0} \rightarrow{ }^{5} \mathrm{D}_{2}$ transition which appears at $463.8 \mathrm{~nm}$ in the excitation spectrum of pure $\left[\mathrm{Eu}(\mathrm{TTA})_{3}\left(\mathrm{H}_{2} \mathrm{O}\right)_{2}\right]$ complex. On the other hand, in the excitation spectrum of doped hybrid film, the band at $463.8 \mathrm{~nm}$ does not appear once it is even weaker by comparison with the strongest

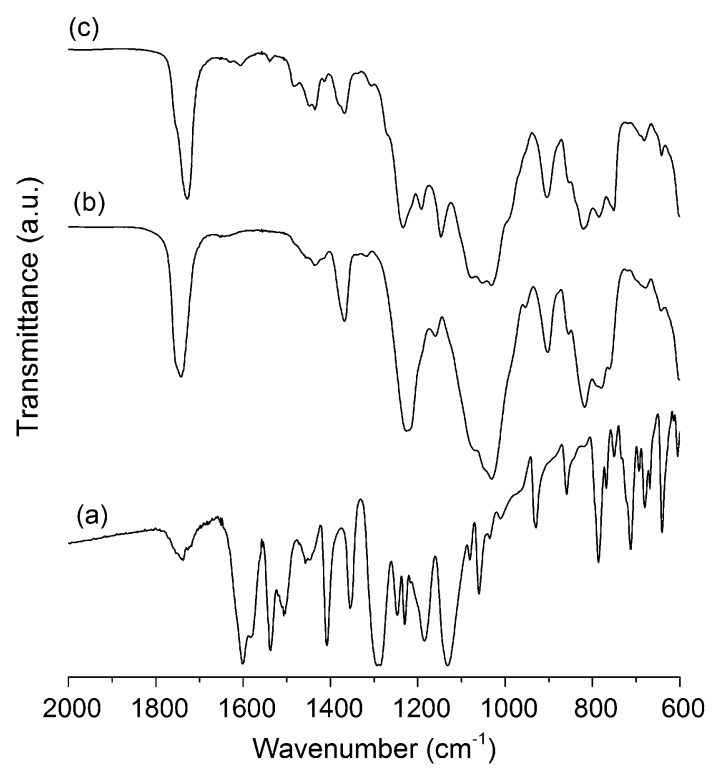

Fig. 9 Fourier transform infrared spectra of $a$ [Eu(TTA $)_{3}\left(\mathrm{H}_{2} \mathrm{O}\right)_{2}$ ] powder, $b$ CA-GPTMS $40 \%$ and, $c$ CA-GPTMS $40 \%$ doped with $\left[\mathrm{Eu}(\mathrm{TTA})_{3}\left(\mathrm{H}_{2} \mathrm{O}\right)_{2}\right] 2 \mathrm{wt} \%$ 

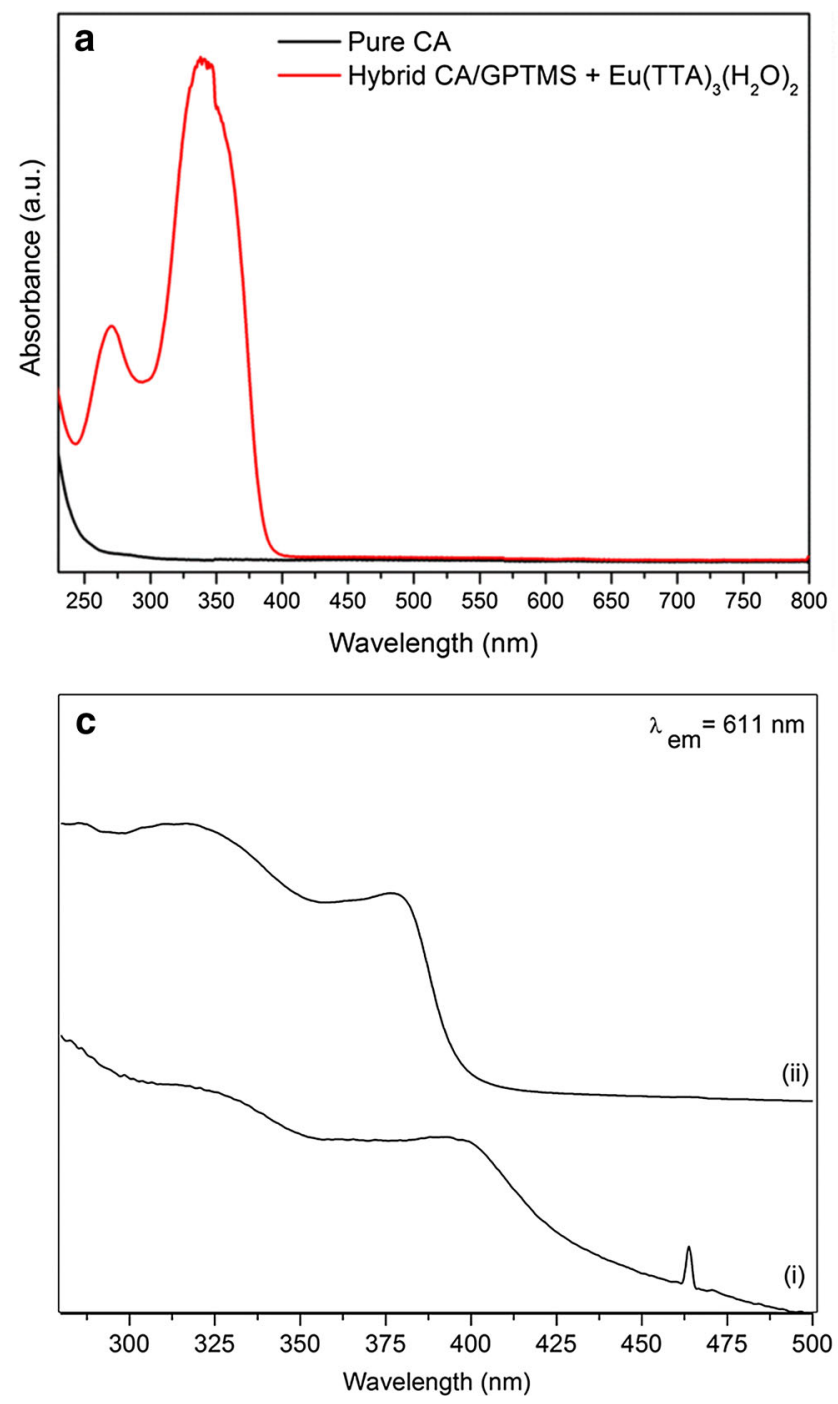

Fig. 10 a Absorption spectra and luminescent CA-GPTMS $40 \%$ hybrid film containing $\mathrm{Eu}(\mathrm{TTA})_{3}\left(\mathrm{H}_{2} \mathrm{O}\right)_{2} 2 \mathrm{wt} \%$ and pristine CAGPTMS $40 \%$ films. b Picture of luminescent CA-GPTMS hybrid

one. The luminescence sensitization via ligand excitation is more efficient than the direct excitation of $\mathrm{Eu}^{3+}$ ion absorption levels owing to the high relative intensity of broad band associated with the ligand level when compared to $4 f-4 f$ absorptions bands of $\mathrm{Eu}^{3+}$ ion [33]. The ratio between the relative intensities of the broad bands attributable to the ligand level and the intrinsic bands of metal ion can provide the efficiency of this effect [34-36].

The emission spectrum of luminescent CA-GPTMS hybrid film featured in Fig. 10d shows similar emission spectrum comparing with pure $\left[\mathrm{Eu}(\mathrm{TTA})_{3}\left(\mathrm{H}_{2} \mathrm{O}\right)_{2}\right]$ complex. It is important to note that the emission spectrum of pure $\left[\mathrm{Eu}(\mathrm{TTA})_{3}\left(\mathrm{H}_{2} \mathrm{O}\right)_{2}\right]$ complex displays higher resolution due to the additional separation caused by the Stark effect. The emission spectra with excitation at $325 \mathrm{~nm}$ are characterized by the transitions ${ }^{5} \mathrm{D}_{0} \rightarrow{ }^{7} \mathrm{~F}_{\mathrm{J}}(J=0,1,2,3$
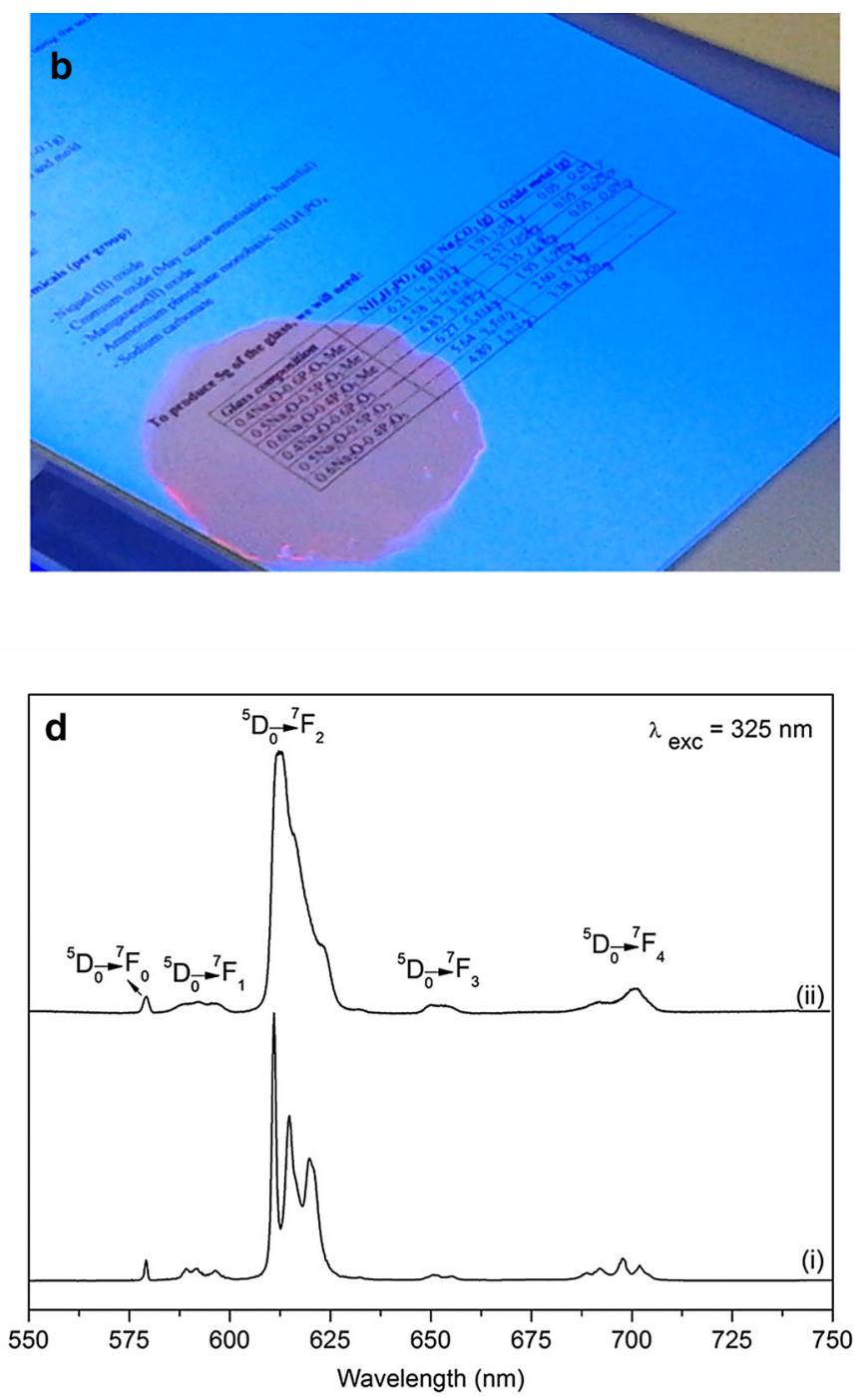

under ultraviolet light exposure $\left(\lambda_{\max }=360 \mathrm{~nm}\right)$, c excitation, and d emission spectra of $i$ pure $\operatorname{Eu}(\mathrm{TTA})_{3}\left(\mathrm{H}_{2} \mathrm{O}\right)_{2}$ complex and $i i$ luminescent CA-GPTMS hybrid film (Color figure online)

and 4) with predominant hypersensitive ${ }^{5} \mathrm{D}_{0} \rightarrow{ }^{7} \mathrm{~F}_{2}$ transition band around $612 \mathrm{~nm}$. These transitions appear in ${ }^{5} \mathrm{D}_{0} \rightarrow{ }^{7} \mathrm{~F}_{0}(579 \mathrm{~nm}),{ }^{5} \mathrm{D}_{0} \rightarrow{ }^{7} \mathrm{~F}_{1}(589,591$ and $596 \mathrm{~nm})$, ${ }^{5} \mathrm{D}_{0} \rightarrow{ }^{7} \mathrm{~F}_{2}(611,614$ and $619 \mathrm{~nm}){ }^{5} \mathrm{D}_{0} \rightarrow{ }^{7} \mathrm{~F}_{3}$ (651 and $655 \mathrm{~nm})$ and ${ }^{5} \mathrm{D}_{0} \rightarrow{ }^{7} \mathrm{~F}_{4}(688,691,697$ and $701 \mathrm{~nm})$ for the pure $\left[\mathrm{Eu}(\mathrm{TTA})_{3}\left(\mathrm{H}_{2} \mathrm{O}\right)_{2}\right]$ complex and ${ }^{5} \mathrm{D}_{0} \rightarrow{ }^{7} \mathrm{~F}_{0}$ $(579 \mathrm{~nm}),{ }^{5} \mathrm{D}_{0} \rightarrow{ }^{7} \mathrm{~F}_{1} \quad(592 \mathrm{~nm}),{ }^{5} \mathrm{D}_{0} \rightarrow{ }^{7} \mathrm{~F}_{2} \quad(612 \mathrm{~nm})$ ${ }^{5} \mathrm{D}_{0} \rightarrow{ }^{7} \mathrm{~F}_{3}(653 \mathrm{~nm})$ and ${ }^{5} \mathrm{D}_{0} \rightarrow{ }^{7} \mathrm{~F}_{4}(692$ and $701 \mathrm{~nm})$ for the luminescent CA-GPTMS hybrid film. The incorporation of the complex into the hybrid leads to an inhomogeneous broadening of the corresponding emission lines. This effect is addressed to the heterogeneous distribution of sites the $\mathrm{Eu}^{3+}$ ions present into the CA-GPTMS hybrid film.

Figure 11 shows the emission decay curves of pure $\left[\mathrm{Eu}(\mathrm{TTA})_{3}\left(\mathrm{H}_{2} \mathrm{O}\right)_{2}\right]$ complex and luminescent CA-GPTMS 
hybrid film. The luminescence decay curves were acquired by monitoring the hypersensitive ${ }^{5} \mathrm{D}_{0} \rightarrow{ }^{7} \mathrm{~F}_{2}$ transition at $611 \mathrm{~nm}$ under excitation at $325 \mathrm{~nm}$. Decay curves follow monoexponential decay law, and the decay times values so obtained are listed in Table 1 . These values are very close together, giving evidence that the complex [Eu(TTA) 3 $\left.\left(\mathrm{H}_{2} \mathrm{O}\right)_{2}\right]$ does not experience major changes when incorporated into the hybrid matrix. In order to get further details on the $\mathrm{Eu}^{3+}$ ion chemical environment in the pure $\left[\mathrm{Eu}(\mathrm{TTA})_{3}\left(\mathrm{H}_{2} \mathrm{O}\right)_{2}\right]$ compound and luminescent hybrid film, some spectroscopy parameters were determined. Experimental Judd-Ofelt intensity parameters $\left(\Omega_{2}\right.$ and $\left.\Omega_{4}\right)$, radiative $\left(A_{\mathrm{rad}}\right)$ and non-radiative $\left(A_{\mathrm{nrad}}\right)$ decay rates and quantum efficiency $(\eta)$ are also listed in Table 1 . For $A_{0 \rightarrow J}$ calculation, Eq. (1) was considered [37]:

$A_{0 \lambda}=\frac{v_{01}}{v_{0 \lambda}} \cdot \frac{S_{0 \lambda}}{S_{01}} \cdot\left(A_{01}\right)$

where $\sigma_{0 \rightarrow 1}$ and $\sigma_{0 \rightarrow J}$ correspond to energy barycenters of ${ }^{5} \mathrm{D}_{0} \rightarrow{ }^{7} \mathrm{~F}_{1}$ and ${ }^{5} \mathrm{D}_{0} \rightarrow{ }^{7} \mathrm{~F}_{\mathrm{J}}$, respectively. $S_{0 \rightarrow 1}$ and $S_{0 \rightarrow J}$ are emission curve areas corresponding to ${ }^{5} \mathrm{D}_{0} \rightarrow{ }^{7} \mathrm{~F}_{1}$ and ${ }^{5} \mathrm{D}_{0} \rightarrow{ }^{7} \mathrm{~F}_{\mathrm{J}}$ transitions, respectively [32]. As known, the magnetic dipole allowed ${ }^{5} \mathrm{D}_{0} \rightarrow{ }^{7} \mathrm{~F}_{1}$ transition which was taken from Ref. [38], since $A_{0 \rightarrow 1}$ rate is almost insensitive to chemical environment changes around the $\mathrm{Eu}^{3+}$ ion with $A_{0 \rightarrow 1} \cong 50 \mathrm{~s}^{-1}$. The experimental intensity parameters $\Omega_{\lambda}$ ( $\lambda=2$ and 4) were estimated from the ${ }^{5} \mathrm{D}_{0} \rightarrow{ }^{7} \mathrm{~F}_{2}$ and ${ }^{5} \mathrm{D}_{0} \rightarrow{ }^{7} \mathrm{~F}_{4}$ transitions, respectively, in the emission spectrum of the $\mathrm{Eu}^{3+}$ complex. The experimental intensities parameters were calculated from the spontaneous emission coefficients $\left(A_{0 \rightarrow J}\right)$, according to the following expression [31]:

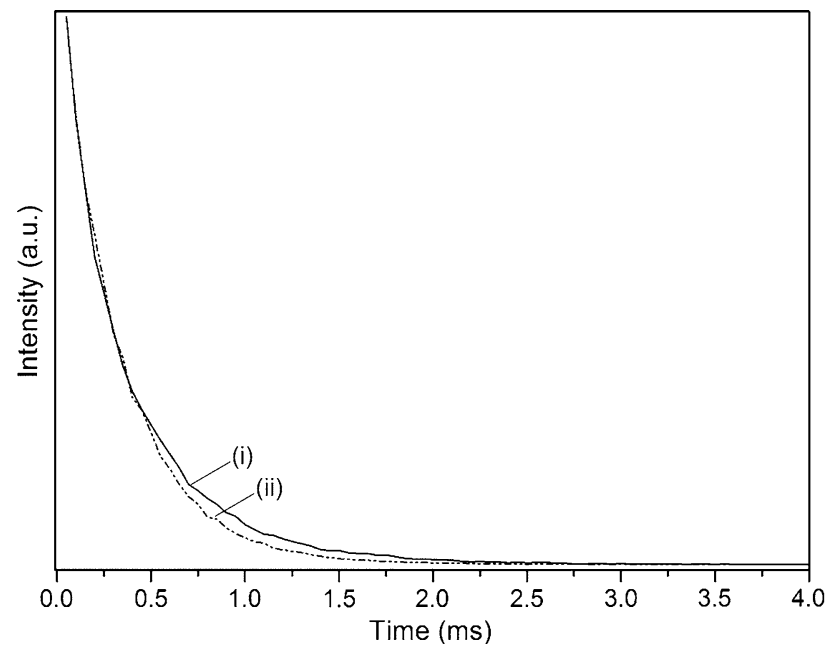

Fig. 11 Emission decay curves $(i)$ pure $\left[\mathrm{Eu}(\mathrm{TTA})_{3}\left(\mathrm{H}_{2} \mathrm{O}\right)_{2}\right]$, and $(i i)$ CA-GPTMS $40 \%$ hybrid film containing $2 \mathrm{wt} \%$ of [Eu(TTA $)_{3}\left(\mathrm{H}_{2}\right.$ $\mathrm{O})_{2}$ ]. The emission lifetime was recorded by monitoring the emission at $611 \mathrm{~nm}$ under excitation at $325 \mathrm{~nm}$
$\Omega_{\lambda}=\frac{3 \hbar c^{3} A_{0 \rightarrow J}}{4 \mathrm{e}^{2} \omega^{3} \chi\left\langle\left\|U^{(\lambda)}\right\|\right\rangle^{2}}$

where $\omega$ is the angular frequency of the transition, $e$ is the electronic charge, $c$ is the velocity of light, $\hbar$ is Planck's constant over $2 \pi, \chi$ is the Lorentz local field correction term, given by

$\chi=\frac{n(n+2)^{2}}{9}$

and $\left\langle{ }^{7} F_{J}\left\|U^{(\lambda)}\right\|{ }^{5} D_{0}\right\rangle^{2}$ is a squared reduced matrix element with value of 0.0032 for the ${ }^{5} \mathrm{D}_{0} \rightarrow{ }^{7} \mathrm{~F}_{2}$ transition and 0.0023 for the ${ }^{5} \mathrm{D}_{0} \rightarrow{ }^{7} \mathrm{~F}_{4}$ one and $\Omega_{\lambda}$ are the Judd-Ofelt intensity parameters $[39,40]$. The refraction index $(n)$ has been assumed equal to 1.5 . In this work, the ${ }^{5} \mathrm{D}_{0} \rightarrow{ }^{7} \mathrm{~F}_{6}$ transition was not observed experimentally; consequently, the experimental $\Omega_{6}$ parameter could not be estimated. Based on the emission spectrum and lifetime of ${ }^{5} \mathrm{D}_{0}$ emitting level, the emission quantum efficiency $(\eta)$ of pure $\left[\mathrm{Eu}(\mathrm{TTA})_{3}\left(\mathrm{H}_{2} \mathrm{O}\right)_{2}\right]$ complex and luminescent CA-GPTMS hybrid film was determined. Initially, the emission coefficients $\mathrm{A}_{02}$ and $\mathrm{A}_{04}$ corresponding to ${ }^{5} \mathrm{D}_{0} \rightarrow{ }^{7} \mathrm{~F}_{2}$ and ${ }^{5} \mathrm{D}_{0} \rightarrow{ }^{7} \mathrm{~F}_{4}$ transitions, respectively, were calculated according to Eq. 1. Considering the ratio between the emitting state lifetime and total decay rate $\left(A_{\text {total }}=1 /\right.$ $\left.\tau=A_{\text {rad }}+A_{\text {nrad }}\right)$, the $\eta$ value can be calculated by Eq. 4 [33]:

$\eta=\frac{A_{\mathrm{rad}}}{A_{\mathrm{rad}+} A_{\mathrm{nrad}}}$

The values of experimental intensity parameters $\Omega_{2}$ and $\Omega_{4}$ and quantum efficiency $(\eta)$ obtained for the $\mathrm{Eu}^{3+}$ complex are similar than the luminescent hybrid film, and they are in accordance with the literature [31]. These results indicate that molecular structure of $\mathrm{Eu}^{3+} \beta$-diketonate complex incorporated into the CA-GPTMS $40 \%$ hybrid film is preserved upon the incorporation, as well as their photoluminescence properties. Accordingly, CAGPTMS is an interesting hybrid matrix to incorporate molecular lanthanide complexes. Our findings demonstrated that the combination of cellulose acetate polymer and 3-glycidoxypropyltrimethoxysilane gathers to the design of new hybrid material with superior properties ascribed by high flexibility and also transparency in the visible to near-infrared region even at high content of reactive epoxy and methoxysilane functions. The hybrid also meets the requirements to host luminescent complex with minimal deleterious effect on the fluorescence efficiency. This multifunctional hybrid material could find potential applications in different areas as flexible phosphors and UV-visible energy converting devices. 
Table 1 Experimental intensity parameters $\left(\Omega_{\lambda}\right)$, emission quantum efficiencies $(\eta)$, lifetimes $(\mathrm{ms})$, radiative $\left(A_{\text {rad }}\right)$, non-radiative $\left(A_{\text {nrad }}\right)$ and total $\left(A_{\text {total }}\right)$ emission coefficient rates for the $\left[\mathrm{Eu}(\mathrm{TTA})_{3}\right.$
$\left(\mathrm{H}_{2} \mathrm{O}\right)_{2}$ ] complex and CA-GPTMS $40 \%$ hybrid film containing $\left[\mathrm{Eu}(\mathrm{TTA})_{3}\left(\mathrm{H}_{2} \mathrm{O}\right)_{2}\right] 2 \mathrm{wt} \%$ based on emission spectra recorded at $298 \mathrm{~K}$

\begin{tabular}{llllllll}
\hline Samples & $\Omega_{2}\left(10^{-20} \mathrm{~cm}^{2}\right)$ & $\Omega_{4}\left(10^{-20} \mathrm{~cm}^{2}\right)$ & $A_{\text {rad }}\left(\mathrm{s}^{-1}\right)$ & $A_{\text {nrad }}\left(\mathrm{s}^{-1}\right)$ & $A_{\text {total }}\left(\mathrm{s}^{-1}\right)$ & $\tau(\mathrm{ms})$ & $\eta(\%)$ \\
\hline [Eu(TTA) ${ }_{3}\left(\mathrm{H}_{2} \mathrm{O}_{2}\right]$ & 18.4 & 7.42 & 782.92 & 2411.96 & 3194.88 & 0.27 & 21 \\
CA-GPTMS 40 \% Eu & 16.8 & 5.14 & 684.39 & 2239.58 & 2923.97 & 0.31 & 22
\end{tabular}

The calculated parameters have deviations of $\pm 10 \%$

\section{Conclusions}

Flexible and transparent films were obtained from CA and GPTMS. These films presented high transparency, as presented in UV-Vis-NIR spectra. AFM images showed increase in the roughness and size of homogeneously dispersed globular-like domains with the relative increase in GPTMS content. XRD patterns showed that higher amounts of GPTMS turn these films more amorphous (in comparison with the neat CA ones). Spectroscopy results (vibrational spectroscopy, ${ }^{13} \mathrm{C}$ and ${ }^{29} \mathrm{Si} \mathrm{CP}-\mathrm{MAS}$ spectra) suggest that epoxy groups mostly remain intact, and significant amount of methoxysilane groups are available after addition of GPTMS in CA. Decomposition temperature occurs around $374{ }^{\circ} \mathrm{C}$ for all films. The presence of reactive epoxy groups and non-hydrolyzed GPTMS molecules highlights the multi-functionality of the prepared films for further modifications. Luminescent films were obtained by incorporating $\mathrm{Eu}^{3+}$ luminescent complex. The calculated spectroscopic parameters of luminescent hybrid were similar to the pure $\mathrm{Eu}^{3+}$ complex, suggesting that the CAGPTMS hybrids are suitable to photonic applications.

Acknowledgments This work was supported by the Brazilian agencies: Coordenação de Aperfeiçoamento de Pessoal de Nível Superior (CAPES), Conselho Nacional de Desenvolvimento Científico e Tecnológico (CNPq). R. R. Silva and M. V. dos Santos thank to Fundação de Amparo à Ciência e Tecnologia do Estado de São Paulo (FAPESP) for the Grant Nos. 2013/12367-6 and 2014/12424-2, respectively. A. Tercjak acknowledges FAPESP for a visiting professor Grant No. 2014/24692-1.

\section{References}

1. Wegst UGK, Bai H, Saiz E et al (2014) Bioinspired structural materials. Nat Mater 14:23-36. doi:10.1038/nmat4089

2. Carro L, Hablot E, Coradin T (2014) Hybrids and biohybrids as green materials for a blue planet. J Sol Gel Sci Technol 70:263-271. doi:10.1007/s10971-013-3153-z

3. Ganster J, Fink H (2013) Cellulose and cellulose acetate. In: Biobased plastics: materials and applications. John Wiley \& Sons Ltd, Chichester, pp 35-62

4. Rodrigues Filho G, Monteiro DS, Meireles CDS et al (2008) Synthesis and characterization of cellulose acetate produced from recycled newspaper. Carbohydr Polym 73:74-82. doi:10.1016/j. carbpol.2007.11.010
5. Lova P, Manfredi G, Boarino L et al (2015) Hybrid ZnO:polystyrene nanocomposite for all-polymer photonic crystals. Phys Status Solidi 12:158-162. doi:10.1002/pssc.201400209

6. Unno N, Mäkelä T, Taniguchi J (2014) Thermal roll-to-roll imprinted nanogratings on plastic film. J Vac Sci Technol B Nanotechnol Microelectron Mater Process Meas Phenom 32:6. doi:10.1116/1.4897132

7. Cook PM, Kelley SS (1992) Grafted cellulose esters containing a silicon moiety. U.S. Patent 5082914

8. Shojaie SS, Rials TG, Kelley SS (1995) Preparation and characterization of cellulose acetate organic/inorganic hybrid films. J Appl Polym Sci 58:1263-1274. doi:10.1002/app.1995.0705 80807

9. Aparecida da Silva C, Maria Favaro M, Pagotto Yoshida IV, do Carmo Gonçalves M (2011) Nanocomposites derived from cellulose acetate and highly branched alkoxysilane. J Appl Polym Sci 121:2559-2566. doi:10.1002/app.33974

10. Zoppi RA, Gonçalves MC (2002) Hybrids of cellulose acetate and sol-gel silica: morphology, thermomechanical properties, water permeability, and biodegradation evaluation. J Appl Polym Sci 84:2196-2205. doi:10.1002/app.10427

11. Heikkinen JJ, Riihimäki TA, Määttä JAE et al (2011) Covalent biofunctionalization of cellulose acetate with thermostable chimeric avidin. ACS Appl Mater Interfaces 3:22402245. doi:10.1021/am200272u

12. Achoundong CSK, Bhuwania N, Burgess SK et al (2013) Silane modification of cellulose acetate dense films as materials for acid gas removal. Macromolecules 46:5584-5594. doi:10.1021/ma40 10583

13. Charles RG, Ohlmann RC (1965) Europium thenoyltrifluoroacetonate, preparation and fluorescence properties. J Inorg Nucl Chem 27:255-259. doi:10.1016/0022-1902(65)80222-6

14. Silverstein RM, Webster FX, Kiemle D (2005) Spectrometric identification of organic compounds, 7th edn. John Wiley and Sons Ltd, New York, p 512

15. Sapić IM, Bistricić L, Volovsek V et al (2009) DFT study of molecular structure and vibrations of 3-glycidoxypropyltrimethoxysilane. Spectrochim Acta A Mol Biomol Spectrosc 72:833-840. doi:10.1016/j.saa.2008.11.032

16. Toprak C, Agar JN, Falk M (1979) State of water in cellulose acetate membranes. J Chem Soc Faraday Trans 1 Phys Chem Condens Phases 75:803-815. doi:10.1039/f19797500803

17. Firsov SP, Zhbankov RG (1982) Raman spectra and physical structure of cellulose triacetate. J Appl Spectrosc 37:940-947. doi:10.1007/BF00663171

18. Socrates G (2004) Infrared and Raman characteristic group frequencies: tables and charts. John Wiley \& Sons Ltd, Chichester, p 342

19. Zhang K, Feldner A, Fischer S (2011) FT Raman spectroscopic investigation of cellulose acetate. Cellulose 18:995-1003. doi:10. 1007/s10570-011-9545-8

20. Riegel B, Blittersdorf S, Kiefer W et al (1998) Kinetic investigations of hydrolysis and condensation of the glycidoxypropyltrimethoxysilane/aminopropyltriethoxy-silane system by means 
of FT-Raman spectroscopy I. J Non Cryst Solids 226:76-84. doi:10.1016/S0022-3093(97)00487-0

21. Kono H, Erata T, Takai M (2002) CP/MAS 13 C NMR study of cellulose and cellulose derivatives. 2. Complete assignment of the $13 \mathrm{C}$ resonance for the ring carbons of cellulose triacetate polymorphs. J Am Chem Soc 124:7512-7518. doi:10.1021/ja010705g

22. Kono H, Yunoki S, Shikano T et al (2002) CP/MAS 13 C NMR study of cellulose and cellulose derivatives. 1. Complete assignment of the CP/MAS $13 \mathrm{C}$ NMR spectrum of the native cellulose. J Am Chem Soc 124:7506-7511. doi:10.1021/ja0 10704o

23. Keely CM, Zhang X, McBrierty VJ (1995) Hydration and plasticization effects in cellulose acetate: a solid-state NMR study. J Mol Struct 355:33-46. doi:10.1016/0022-2860(95)08865-S

24. Williams EA (1984) Recent advances in silicon-29 NMR spectroscopy. Annu Reports NMR Spectrosc 15:235-289. doi:10. 1016/S0066-4103(08)60209-4

25. Innocenzi P, Brusatin G, Babonneau F (2000) Competitive polymerization between organic and inorganic networks in hybrid materials. Chem Mater 12:3726-3732. doi:10.1021/cm001139b

26. Barud HS, de Araújo Júnior AM, Santos DB et al (2008) Thermal behavior of cellulose acetate produced from homogeneous acetylation of bacterial cellulose. Thermochim Acta 471:61-69. doi:10.1016/j.tca.2008.02.009

27. Sassi J-F, Chanzy H (1995) Ultrastructural aspects of the acetylation of cellulose. Cellulose 2:111-127. doi:10.1007/BF0081 6384

28. Wu H, Fang X, Zhang $X$ et al (2008) Cellulose acetate-poly $(N$ vinyl-2-pyrrolidone) blend membrane for pervaporation separation of methanol/MTBE mixtures. Sep Purif Technol 64:183-191. doi:10.1016/j.seppur.2008.09.013

29. Wang J, Fan X, Tian W et al (2011) Ring-opening polymerization of $\gamma$-glycidoxypropyltrimethoxysilane catalyzed by multi-metal cyanide catalyst. J Polym Res 18:2133-2139. doi:10.1007/ s10965-011-9623-5

30. Yamazaki R, Karyu N, Noda M et al (2016) Quantitative measurement of physisorbed silane on a silica particle surface treated with silane coupling agents by thermogravimetric analysis. J Appl Polym. doi:10.1002/app.43256
31. Malta OL, Brito HF, Menezes JFS et al (1997) Spectroscopic properties of a new light-converting device Eu(thenoyltrifluoroacetonate) ${ }_{3} 2$ (dibenzyl sulfoxide). A theoretical analysis based on structural data obtained from a sparkle model. J Lumin 75:255-268. doi:10.1016/S0022-2313(97)00107-5

32. Teotonio EES, Fett GM, Brito HF et al (2008) Evaluation of intramolecular energy transfer process in the lanthanide(III) bisand tris-(TTA) complexes: Photoluminescent and triboluminescent behavior. J Lumin 128:190-198. doi:10.1016/j.jlumin.2007. 07.005

33. de Sá G, Malta O, de Mello Donegá C et al (2000) Spectroscopic properties and design of highly luminescent lanthanide coordination complexes. Coord Chem Rev 196:165-195. doi:10.1016/ S0010-8545(99)00054-5

34. Molina C, Dahmouche K, Messaddeq Y et al (2003) Enhanced emission from $\mathrm{Eu}(\mathrm{III}) \beta$-diketone complex combined with ethertype oxygen atoms of di-ureasil organic-inorganic hybrids. J Lumin 104:93-101. doi:10.1016/S0022-2313(02)00684-1

35. Caiut JMA, Barud HS, Santos MV et al (2011) Luminescent multifunctional biocellulose membranes. Proc SPIE 8104, Nanostructured Thin Films IV, 81040Z. doi:10.1117/12.895418

36. Carlos LD, Messaddeq Y, Brito HF et al (2000) Full-color phosphors from europium(III)-based organosilicates. Adv Mater 12:594-598. doi:10.1002/(SICI)1521-4095(200004)12:8<594: AID-ADMA594>3.0.CO;2-S

37. de Mello Donegá C, Junior SA, de Sá G (1997) Synthesis, luminescence and quantum yields of $\mathrm{Eu}(\mathrm{III})$ mixed complexes with 4,4,4-trifluoro-1-phenyl-1,3-butanedione and 1,10-phenanthroline-N-oxide. J Alloys Compd 250:422-426. doi:10.1016/ S0925-8388(96)02562-5

38. Raj DBA, Biju S, Reddy MLP (2008) One-, two-, and threedimensional arrays of $\mathrm{Eu} 3+-4,4,5,5,5$-pentafluoro-1-(naphthalen-2-yl)pentane-1,3-dione complexes: synthesis, crystal structure and photophysical properties. Inorg Chem 47:80918100. doi:10.1021/ic8004757

39. Judd BR (1962) Optical absorption intensities of rare-earth ions. Phys Rev 127:750-761. doi:10.1103/PhysRev002E127.750

40. Ofelt GS (1962) Intensities of crystal spectra of rare-earth ions. J Chem Phys 37:511-520. doi:10.1063/1.1701366 